\title{
Crítica social y religiosa en el profeta Amós: una relectura profética en Latinoamérica
}

\author{
Social and religious criticism in the prophet Amós: \\ a prophetic relecture in Latin america \\ Emivaldo Silva Nogueira \\ Pontificia Universidad Católica de Chile-CHILE \\ filliusorion@hotmail.com \\ Valmor da Silva \\ Pontificia Universidad Católica de Goiás-BRASIL \\ valmor@pucgoias.edu.br
}

\section{Resumen}

En este artículo visitaremos, exegéticamente, la realidad donde Amos hace su experiencia profética, y cómo esta experiencia se manifiesta exegéticamente hoy en la realidad latinoamericana, especialmente con respecto a los problemas de injusticia social. En este sentido, es necesario comprender los conflictos experimentados por el profeta Amós y las autoridades políticas religiosas de Israel en ese siglo octavo antes de Cristo, que usurpó los derechos de los pobres, las viudas y los huérfanos. Amós se convierte en el profeta de la justicia social, el libro bíblico que lleva su nombre da testimonio de esto. Como portavoz de la deidad de Israel, Amos se vuelve duro, estricto e imperativo. Tomando como referencia el contexto amosiano, podemos leer las realidades de América Latina. Por medios analíticos, trataremos de comprender cómo las palabras del león del sur pueden aplicarse a los problemas de injusticia que se experimentan en tierras sudamericanas. Nuestra hipótesis es que, ya sea en el siglo VIII a. C. o ahora en el siglo XXI, las experiencias bíblicas siguen siendo referencias cuando se trata de la lucha por la justicia, el orden y la moral para los hombres de todos los tiempos. El orden para la justicia social hoy y ayer sigue siendo imperativo e insinúa a quienes piensan en un mundo mejor.

Palabras clave: justicia; amós; América Latina; profetas, religión

\section{Abstract}

In this article we will visit, exegetically, the reality where Amos makes his prophetic experience, and how this experience manifests itself exegetically today in the Latin American reality, especially with regard

Emivaldo Silva Nogueira $\cdot$ Valmor da Silva

Crítica social y religiosa en el profeta Amós: una relectura profética en Latinoamérica. Autoctonía. Revista de Ciencias Sociales e Historia, Vol. IV, N 1, Enero-Junio 2020, 77-90 ISSN 0719-8213

DOI: http://dx.doi.org/10.23854/autoc.v4il.154 
to issues of social injustice. In this sense, it is necessary to understand the conflicts experienced by the prophet Amos and the religious political authorities of Israel in that eighth century BC, which usurped the rights of the poor, widows and orphans. Amos becomes the prophet of social justice, the biblical book bearing his name bears witness to this. As spokesman for the deity of Israel, Amos becomes hard, strict, and imperative. Taking the Amosian context as a reference, we can read the realities of Latin America. By analytical means we will try to understand how the words of the southern lion can be applied to the issues of injustice experienced in South American lands. Our hypothesis is that, whether in the eighth century $\mathrm{BC}$ or now in the twenty-first century, biblical experiences are still references when it comes to the struggle for justice, order and morality for men of all times. The order for social justice today and yesterday is still imperative and intimates those who think of a better world.

Keywords: justice; amos; Latin America; prophet; religion

Recibido: 30 de Septiembre de 2019 • Aceptado: 04 de Noviembre de 2019

\section{Introducción}

Conozco tus innumerables ofensas

$y$ tus enormes pecados!

Acosan a los justos, aceptan el soborno, y repeler a los pobres en la puerta (Am 5,12)․․

Una mirada rápida a América Latina revela contradicciones y ambigüedades. Campañas políticas prometedoras ocultan los esquemas de corrupción criminal. Las Reformas sociales engañosas echan en la marginalidad multitudes de pobres y miserables. El aumento de la riqueza de unos pocos profundiza la distancia de la mayoría pobre. Los líderes religiosos sin escrúpulos explotan la fe y las creencias de los pueblos del continente. La lista de injusticias es demasiado conocida para extenderse aún más.

Se puede buscar un espejo de esta realidad en la profecía de Amós, contextualizada en el siglo VIII
a.C. A pesar de los casi tres milenios de distancia, el profeta enfrentó contradicciones similares a las nuestras. Él ve a la sociedad como una canasta de higos maduros, a punto de caer (Am 8,1-3). La prosperidad económica de los ricos contrasta con la realidad de las personas, pobres, miserables, indigentes ('ebion, 2,$6 ; 4,1 ; 5,12 ; 8,4,6$ ), pobres, débiles (dal, 2,$7 ; 4,1 ; 5,11 ; 8,6)$ y pobre, humilde ('naw, 2.7). Amós se involucra en la lucha social y la denuncia de la injusticia, lo que lo convierte en un profeta "conocido" para nosotros, según Reimer (2000: 172).

El momento histórico de Amós fue de prosperidad económica y tranquilidad política para el Reino de Israel. Pero también fue una época de descomposición social y corrupción religiosa, según Alonso Schökel y Sicre Diaz (1991: 981-982). Amós ilustra el caos de esta sociedad en la cual los jueces en la puerta de la ciudad vendieron los derechos de los débiles (Am 2,6; 5,7,10-12); los 
acreedores redujeron sus deudores a esclavos (Am $2,6)$ o prometieron sus propiedades (Am 2,8); los mercaderes devoraron a los pobres (Am 8,4-6). Amós también denuncia la corrupción religiosa en la que los becerros de oro en los santuarios de Betel (Am 4,4; 5,5; 7,10), Dan (Am 8,14) y Guilgal (Am 4,4; 5,5) representó a Yahweh y favoreció la mala conducta. Amós denuncia la suntuosidad de las fiestas populares (Am 5,21-22; 8,5) asociadas con prácticas inmorales e injusticias (Am 2,7).

Ante esta situación social y religiosa, Amós ataca como un león. Comienza en el nombre de Dios que declara: "Yahweh rugirá desde Sión" (Am 1,2). La palabra es igualmente efectiva: “¿Rugió un león en el bosque sin su presa?" (Am 3,4). Su vocación no es diferente: "ruge un león: ¿Quién no temerá? El Señor Yahweh dijo: ¿Quién no profetizará?" (Am 3,8). La esperanza de salvación de Israel será mínima: "Como un pastor salva de la boca del león dos piernas o una oreja” (Am 3,12). El juicio de Yahweh será fatal, así: "Como quien huye de un león, y un oso cae sobre él" (Am 5,19). Aldina Silva (2001: 20) afirma a partir de esta metáfora: “Dios es el león, Amós el pequeño león”. Significa que la vocación profética es inmediata y efectiva frente a la violencia y la opresión. Por lo tanto, se le llama el "profeta de la justicia"2.

Amós se levanta como un paladín dela justicia. En la antigüedad, especialmente en la Edad Media, los guerreros dedicados a promover el bien y la justicia se llamaban paladines. Eran centinelas, luchaban contra las fuerzas del mal donde se presentaban y defendían a los más indefensos. Sobre todo, los paladines eran personas justas. "El término caracteriza a los individuos, séniores palatii u optimates o primates palatii, en cualquier caso, un grupo de personas seculares que forman el officium palatinum" (Sánchez Albornoz, 1974: 93), componiendo el entorno real y el corazón de la administración del reino.

Aunque esta nomenclatura es históricamente postbíblica, la comprensión y la justicia para los desfavorecidos es ahistórica, cruza horizontes imaginarios y llega a la génesis de la humanidad misma. Los débiles siempre han necesitado protección de los fuertes. Hasta que se volvió normativo, la idea de cuidar y proteger al otro ya estaba atravesando la imaginación primitiva. Ella es antropológica. Es cierto que los fuertes y poderosos no siempre están dispuestos a defender a los débiles, pero siempre ha habido personas que se hicieron cargo de ello. En el contexto bíblico del Antiguo Testamento, los más débiles recibieron protección, con severas prescripciones para quienes los violaron (Schwantes, 2013). La Biblia hebrea se refiere a los pobres con varios sinónimos. También califica tres categorías específicas, que merecen una protección especial de la ley y de la defensa profética: extranjera (ger), huérfana (yatôm) y viuda ('alemanah). Esta tríada social forma un grupo emblemático, con varias referencias bíblicas explícitas (Frizzo, 2011: 17).

Con el desarrollo socio urbano, la burocratización y el contacto con civilizaciones distintas, el israelita bíblico se alejó cada vez más de los preceptos establecidos en el llamado Código de la Alianza. La Alianza establecida ahora dio paso a la violencia, la esclavitud y la lujuria de los fuertes, mientras que los débiles perdieron cada vez más su dignidad y sus vidas. El panorama general era 
de corrupción; imperios de la ciudad devoraron a los pobres agrarios. La injusticia se ha convertido en ley vigente.

Fue en este ambiente, cargado de desigualdad e injusticia, que surgió el profeta Amós. Yahweh convoca "desde medio del rebaño" (Am 7,15), este vaquero y cultivador de sicómoros, como un paladín, para llevar la justicia a Israel. Poseído y justificado por la divinidad, este paladín lanzará ataques tan violentos contra los israelitas que nada puede escapar.

Por lo tanto, en este artículo trataremos la justicia social en la que orbita la profecía de Amós y cómo se relaciona con el sistema religioso corrupto, en el contexto socio histórico israelita del siglo VIII a.C., en relación con la realidad social y religiosa de América Latina de nuestros días. Para trazar un camino que nos lleve a este momento histórico, fue necesario recurrir a diferentes materiales bibliográficos, ya sean históricos, teológicos, antropológicos, sociológicos y hermenéuticos, para abarcar las diferentes perspectivas que respaldarán nuestra trayectoria. Este proceso revela en sí mismo un trasfondo de contingencias, desafíos y efectos que están directamente relacionados con la historia y los dramas experimentados, tanto en el mundo bíblico como en la contemporaneidad latinoamericana.

Frente a este intento de comprender el mundo de Amós y las múltiples interfaces de las injusticias sociales prevalecientes. En el primer elemento explicaremos cómo la justicia social está envuelta en la arquitectura del libro de Amós. En el segundo ítem, bajo el sesgo analítico-exegético, discutiremos sobre la profecía de Amós contra el sistema religioso corrupto, haciendo un recorte bíblico, finalmente, en el tercer ítem, para entrar en la crítica social del profeta Amós y su contribución a la realidad latinoamericana. Este breve artículo llegará a su fin, sacando algunas conclusiones.

\section{Justicia social en la arquitectura del libro de Amós}

Que el derecho (mishpat) corra como el agua Y la justicia (tsedaqah) como un río que corre

(Am 5,24)

La ley y la justicia a menudo están unidas en los profetas, y particularmente en Amós (5,7.24; 6,12 ). Las palabras hebreas derecho (misfat) y justicia (tsedaqah), además de estar asociadas, son prácticamente sinónimos. Mishfat, de la raíz shafat, se refiere al derecho, la justicia, el juicio y generalmente designa acciones gubernamentales, con más de 400 ocurrencias en la Biblia hebrea. Tsedaqah traduce justicia, rectitud, con la variante masculina tsédeq, y se refiere al estándar ético y moral, siendo que el "justo" es llamado tsaddîa (Verkindère, 2001:16-18).

Derecho y justicia son "como el hilo conductor del plan de Dios en la Biblia" (Aguirre, 1990:546). Esto se confirma a lo largo de la historia bíblica, pero se enfatiza en los profetas, especialmente Amós.

La arquitectura del libro de Amós tiene como base sumaria el reclamo de justicia en sus muchas características. Los diversos comentaristas y estudiosos sobre este paladín de la justicia difieren en 
muchos aspectos en su análisis, pero en uno, casi todos están de acuerdo: el libro del profeta Amós es el libro de la justicia social. En América Latina, en particular, se ha prestado más atención a la crítica social del profeta, la identificación de las víctimas del sistema opresivo y los mecanismos de explotación del antiguo Israel, en comparación con la realidad actual. Se ha resaltado el lugar social del profeta campesino, al igual que su lucha contra el estado opresivo y la religión engañosa (Reimer, 2000: 172).

Es interesante notar que la injusticia social no tiene estación. Parece omnipresente y atemporal. Cuando lees el libro del profeta Amós, tienes la sensación de que fue escrito en esta generación actual. Este documento que forma parte de las Escrituras de los judíos y los cristianos es un grito de protesta contra la injusticia, la opresión y la indiferencia. Amós era una persona valiente. Denunció el abuso social de los poderosos de su época. No le intimidaban los peligros de levantarse contra reyes y sacerdotes. Protestó contra la diferencia polar en la distribución de la riqueza. Reprendió la hipocresía y la práctica religiosa sin amor, misericordia y justicia. Todo esto subyace a una arquitectura didáctica que es atractiva para sus lectores póstumos. Por lo tanto, sus predicciones son utilizadas por profetas, poetas y socialistas de todos los tiempos, incluso aquellos que nunca han conocido sus escritos pero que repiten sus ideas esenciales. Schwantes (2004: 83-111) analiza el clima de "terror total" en Amós, identifica quiénes son "estas personas empobrecidas", y conjetura un grupo de "agricultores organizados" y vislumbra una utopía de "esperanza para los empobrecidos", según la canción final del profeta (Am 9,11-15).

El libro del profeta Amós tiene una composición bastante única, ya que todos sus escritos conllevan una dosis de crítica, debido a la justicia social. Los escritores de este profeta, conscientes o no, idearon una estructura para que la justicia, o la falta de ella, se percibiera en todo el libro. En una relación sincrónico - diacrónica, el libro comienza presentando lo que sucedió en la escena internacional, donde la política desarrolló un papel fundamental, hasta que llegó al corazón de Israel. Por lo tanto, en la base macro de la arquitectura están los oráculos propios de Amós pronunciados contra siete naciones, incluido Israel (Am 1,315; 2,1-16). En estos oráculos, Amós enfatiza la justicia divina, que castiga en todos los pueblos cualquier tipo de injusticia. Casi siempre estuvieron en conflicto, lo que provocó el aumento de las injusticias y las desigualdades. Con este fin, los escritores tomaron el primer y segundo capítulos del libro. En segundo lugar del complejo estructural, se presenta al profeta dirigiéndose a la nación de Israel: condenando a toda la sociedad (Am 3 a 9), haciendo advertencias, lamentaciones y amenazas. En este segundo momento, toda su atención se centrará en este ámbito y, como se relaciona internamente y con los que lo rodean, tales elementos están presentes desde el capítulo tres hasta el noveno.

En la micro base de esta arquitectura se encuentran los estados sociales de Israel. El profeta Amós ahora enfrentará sus mayores golpes contra lo que estaba sucediendo dentro del reino de Israel con respecto a la salvaguarda de la justicia, el 
prototipo divino, con énfasis en la casta sacerdotal. Para Amós, lo que sucedió en esta sociedad fue sinónimo, no solo del olvido de Dios, sino también como resultado de acuerdos internacionales, antes, durante y después de los conflictos bélicos, que hicieron que los más desfavorecidos se volvieran miserables, la mayoría de las veces, esclavos. Todo esto fomentó una transformación en el comportamiento ético y moral, llevando a las castas nobles a someter lo que fuera inferior. Debido a estas derrotas, Amós se dirige a esta nación, haciendo: advertencias y amenazas a Israel (Am 3,1-15); contra las mujeres de Samaria (Am 4,1-3); ilusión, impenitencia, castigo de Israel (Am 4,4-12); llorando sobre Israel (Am 5,1-27); contra la falsa seguridad de los grandes de Israel (Am 6,1-14); las visiones (Am 7,1-17; 8,1-14; 9,1-10) y las perspectivas de restauración y fecundidad paradisíaca (Am 9,11-15).

De una manera más didáctica, resumimos cómo se produjo este complejo arquitectónico y cómo se fusiona en una relación sincrónica diacrónica: Primero, encontramos a las naciones criticadas por Amós en un panorama internacional y nacional. En segundo lugar, su partida de las tierras del reinado de Judá y la elección profética de Israel, el pueblo de Yahweh, para finalmente, en tercer lugar, abordar los estratos sociales de esa monarquía, como Yahweh le había revelado. Dentro de este complejo arquitectónico, tendríamos otras subdivisiones que son muy interesantes para investigar, pero nuestra intención es analizar la corrupción en el sistema social y religioso, en el contexto amosiano, y relacionar dicha corrupción con la praxis social y religiosa en América Latina.

\section{La profecía de Amós contra el sistema religioso corrupto}

La vida profética de Amós fue tomada y conducida por la voluntad irresistible de su Dios, y como estaba poseído por Yahweh, poseyó a Israel y sacudió sus estructuras. La palabra que Yahweh le había ordenado que dijera era principalmente buscar justicia. O se hizo justicia a aquellos que eran los favoritos de Yahweh, sellados en el Código de la Alianza, o Yahweh incluso caería sobre Israel y lo borraría. "Amós profetiza por obligación, no por placer. Está bajo coerción divina 'iRugió el león! ¿Quién no temerá? Yahweh habló! ¿Quién no profetizará? '”(Am 3,8) (Schwantes, 2004: 41).

En algún momento los sacerdotes fueron tocados por la corrupción ${ }^{3}$. En algún momento se dejaron guiar por intereses privados, olvidaron la causa de los pobres, las viudas, los extranjeros hechos de esclavos ${ }^{4}$, es decir, se distanciaron de los problemas menores y el reconocimiento social y comenzaron a legislar a favor de la mayoría de las castas nobles, de los ricos. Esta actitud no solo permitió que la ley se hiciera cumplir injustamente, sino que ayudó a aumentar los problemas sociales, a sobrecargar los impuestos, a dejar de ser olvidados y a profanar la casa de Yahweh, con ritos y adoración a otros dioses 5 . No es sin razón que el profeta Amós se vuelve tan duro en sus afirmaciones ${ }^{6}$.

Ahora bien, si el principio básico de la unción sacerdotal era mantener el culto a Yahweh, darse cuenta del derrocamiento de la justicia social en los tribunales y la desaprobación de los grupos sociales menores era profundamente insoportable 
para nuestro paladín de justicia. Es por eso que el matrimonio entre el sacerdocio y la jurisprudencia en Amós no parece estar justificado:

4Porque así dijo Yahweh a la casa de Israel: ¡Búscame y vivirás!

5Pero no busques a Betel, no entres a Guilgal y no pases por Bersabea; Guilgal será deportado ¡Y Betel se convertirá en una iniquidad! 6 ¡Busca a Yahweh y vivirás! Para que él no entre como fuego en la casa de José

y devorarlo, sin que hay nadie en Bethel para borrarlo!

7Ellos que convierten la ley en veneno ${ }^{7}$ y derriba la justicia por tierra (Am 5,4-7).

Darse cuenta de la corrupción en las instituciones establecidas fue una perspectiva presentada por muchos profetas. No solo en Amós, sino que en general los profetas sabían y denunciaban que ya no se podía contar con las instituciones para mantener la justicia social en su totalidad. Todo el sistema había sido contaminado por la corrupción. Y los sacerdotes, los hombres elegidos institucionalmente para administrar la santidad de los Templos, y para proporcionar la anamnesis constante de la Alianza con Yahweh, ya no podían señalar el camino a la justicia. Como proclama Sicre (1992), las peregrinaciones a los grandes santuarios de Betel, Gilgal y Bersabea tenían una gran atracción para la gente, no ahorraban en diezmos, los sacrificios de animales y abundantes ofrendas ${ }^{8}$. Pero todo este culto va acompañado de tremendas injusticias, errores en el comercio, compra de esclavos y opresión de los desfavorecidos. "Ahora el conflicto se desarrolla dentro delámbito religioso: el antagonismo entre el verdadero profeta y el sacerdote" (Sicre, 1992: 249). Es sobre todo a este respecto que la profecía entra en conflicto con la casta sacerdotal: la de usar su estatus social para la búsqueda de intereses personales, olvidando las razones por las cuales fueron ungidos.

Este choque es evidente en muchos profetas: Samuel (1 Sam 2,12-17), aunque también sacerdote, condenó a los hijos de Elí. Jeremías los consideró "lacayos del poder real"; En Oseas, Dios declara: “Te echaré de mi sacerdocio" (Oseas 4,6; 4,9; 6,9). Miqueas 2,1 registra la misma situación; “¡Ay de aquellos que idean iniquidad y que traman el mal en sus camas! ¡Al amanecer lo practican, porque está en el poder de sus manos!" Estas mismas advertencias se pueden encontrar en: 2 Sam 15,35; Sl 78,64; Sf 1,4; 3,4; Jr 2,26; 5,31; 23,11; 48,7. Pero el caso más emblemático que podemos tomar es el conflicto entre el sacerdote Amasias y el profeta Amós, porque sus propias palabras ya lo acusan y señalan el contexto de cómo se posicionó la casta sacerdotal, especialmente cuando dijo que no al servicio de Dios, pero del rey. Según Amasias, Betel, la casa de Dios, era una casa real:

Entonces Amasias, el sacerdote de Betel, envió a Jeroboam, rey de Israel, diciendo: Amós conspira contra ti en el corazón de la casa de Israel; la tierra ya no puede soportar todas sus palabras. Porque así dijo Amós: "Jeroboam morirá por la espada, e Israel será deportado lejos de su tierra”. Amasias luego le dijo a Amós: "Vidente, vállate y huye a la 
tierra de Judá; come tu pan allí y profetiza allí. Pero en Betel ya no puedes profetizar, porque es el santuario del rey, un templo del reino" (Am 7,10-13).

Neher (1975: 256) afirma que "ninguna expresión verbal podría resaltar mejor el sacrilegio que esto implica: la voluntad del estado reemplaza a la de Dios". Y aquí hay algo nuevo en esta crítica, el principal antagonista del profeta no es el rey, sino el sacerdote. Aquí el rey está más en la sombra, no es él quien habla en contra del escándalo del profeta, sino el sacerdote, porque también se sintió amenazado (Neher, 1975). El Templo ya no podía ser una respuesta a los problemas fundamentales del hombre. Amós informa en los capítulos 3 y 4 que la adoración ya no servía para salvar o para mostrar que la gente estaba en relación con Dios, esto significa que la gente no dependía de la existencia de santuarios sino de la implementación de justicia en los tribunales. Podemos observar eso,

los pobres casi no podían ofrecer los sacrificios obligatorios sin endeudarse, y los santuarios contribuyeron así a la opresión y la explotación de los económicamente débiles. [...] Sin embargo, la institución cultural es para Amós uno de los más responsables de la injusticia, porque promueve la idea del Dios equivocado (Sicre, 1990: 202-203).

Contra la adoración formal, Amós se burló: “ Entra en Betel y peca! ¡En Gilgal, y multiplica tus pecados!" (4,4; cf. 5,5; 7,10). Sentencia contra la adoración falsa: "Los que juran por el pecado de Samaria y los que dicen: ‘'Vive tu Dios, Dan!',

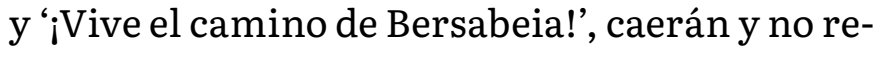
sucitarán" $(8,14)$. Rechaza la adoración disociada de la justicia: "Odio, desprecio tus fiestas y no me gustan tus reuniones” $(5,21)$.

Al comentar sobre esta crítica de Amós y otros profetas de la adoración formal y, a su vez, de sus administradores, la Biblia de Jerusalén (2002, Am 5,21, nota "a") establece, como nota de pie de página, el siguiente descargo de responsabilidad;

Los profetas a menudo se han levantado contra la hipocresía religiosa: muchos creían estar en paz con Dios porque realizaban ciertos ritos de culto (sacrificios, ayunos), sin tener en cuenta los preceptos más elementales de la justicia social y el amor al prójimo (ISm 15,22; Is 1,10-16; 29,13-14; 58,1-8; Os 6,6; Mq 6,5-8; Jr 6,20; J1 2,13; Zc 7,4 -6, cf. Sal $40,7-9 ; 50,5-15 ; 51,18-19)$.

La visión del profeta Isaías (1,10-15), la manera de su predecesor Amós (5,21-27), va en contra de la hipocresía manifestada en la adoración a Dios. El pericope es de su importancia. Sin medir tus palabras, leemos;

10Escuché la palabra de Yahweh, jefe ${ }^{9}$ de Sodoma,

¡Presten atención a las instrucciones de nuestro Dios, pueblo de Gomorra!

11 ¿Cómo me importan tus innumerables sacrificios?, dice Yahweh.

Estoy harto de las ofrendas quemadas de carneros y la grasa de terneros engordados; En la sangre de toros, corderos y cabras no tengo placer. 
12Cuando vienes a mí

¿Quién te pidió que pises mis canchas? 13 Solo tráeme ofrendas vanas:

Son para mí un incienso abominable.

Luna nueva, sábado y asamblea,

¡No soporto la falsedad y la solemnidad!

14Tus lunas nuevas y tus fiestas, mi alma las odia.

son una carga para mí; Estoy cansado de llevarlo.

15Cuando extiendes tus manos, aparto mis ojos;

Aunque multipliques la oración, no te escucharé.

Es importante subrayar que las prácticas religiosas en sí mismas no fueron condenadas por Isaías, ni por Amós, sino que fueron juzgadas negativas cuando no estaban acompañadas por la coherencia de la vida, la observancia diaria de la caridad, el amor al prójimo y el respeto por los derechos de las personas económicamente más débil, ya que había muchas prácticas de adoración, pero no tomaban en cuenta al otro como un fenómeno e imagen divinos. La crítica se dirige más a la religión oficial como mecanismo de opresión y explotación (Reimer, 1992: 54-55).

Aún sobre el texto mencionado de Isaías 1,10-15, Alonso Schökel y Sicre Díaz (1988: 121) presentan un paralelo muy interesante entre lo que, según el texto de Isaías, los sacerdotes realizaban en la adoración y lo que era aceptable a Dios, ya que la marca de la injusticia era evidente en esa sociedad. Dichos escritores exponen este paralelo en dos columnas, y sacaremos de él para argumentar qué tan lejos estaban los funcionarios del templo promoviendo la adoración de la voluntad divina:

\begin{tabular}{|c|c|}
\hline $\begin{array}{l}\text { Sacrificios } \\
\text { holocaustos, grasas } \\
\text { sangre } \\
\text { visita y regalos } \\
\text { regalos } \\
\text { incienso } \\
\text { fiestas } \\
\text { gestos }\end{array}$ & $\begin{aligned} \longrightarrow & \text { estoy harto } \\
\longrightarrow & \text { no me gusta } \\
\longrightarrow & \text { a quien exige? } \\
\longrightarrow & \text { vacío } \\
\longrightarrow & \text { execrable } \\
\longrightarrow & \text { Odio, la carga } \\
\longrightarrow & \text { Cierro los ojos } \\
\longrightarrow & \text { no los escucho } \\
& \text { no me importa }\end{aligned}$ \\
\hline
\end{tabular}

Por lo tanto, es evidente a partir de la lectura del texto, que no faltaron las ceremonias religiosas en Jerusalén. Pero la religión se había transformado en un rito, algo que sucedió dentro del templo, la mera práctica de algún tipo de liturgia, completamente separada de la justicia socialy el respeto al prójimo. La celebración de la adoración tomó el significado de cada religión, la forma tomó el lugar de la esencia, intercambiaron el acto de fe, de creer, con el contenido de la creencia. Los sacerdotes no entendieron que la práctica de la religiosidad y la justicia no era algo que sucedía solo dentro del templo, en un momento, bajo la dirección de una persona en particular, sino en la vida en general.

Es por eso que Amós persistió en la amenaza y la lucha por volver a la justicia, incluso si le causó las más variadas consecuencias, incluso la muerte. Y siguió hablando con la gente en nombre de Dios, y con Dios en nombre de la gente, a veces contra el sistema religioso, a veces contra las otras esferas sociales. Resulta que entre el ideal - el retorno a la justicia -, y el real - mantenimiento del status 
quo -, la corrupción del sistema social y religioso parece cruzar el horizonte histórico y llegar a nuestros días.

\section{La crítica social del profeta Amós: una contri- bución a la realidad latinoamericana}

Las críticas sociales y religiosas hechas por Amós en su tiempo son válidas para todos los tiempos, y especialmente para América Latina hoy, porque tocan los cimientos de las relaciones sociales y las relaciones con Dios.

Dado que "solo Dios es justo y puede hacer justicia" (Deut 32,4), la justicia humana es una imitación de la justicia divina. La justicia no es solo un atributo o cualidad de Dios, sino una revelación de su esencia. Aguirre (1990: 541) hace esta declaración: "Pero creo que el uso de la Biblia es muy importante para entender que el compromiso con la justicia no es un elemento adicional, quizás importado por las modas recientes, sino que surge del corazón de la fe en Dios". Y Vaz (2012: 9) confirma, en otras palabras: "Hay pocos conceptos en toda la Biblia hebrea tan cercanos a Dios como la justicia. Para el israelita creyente, Dios no existe sin justicia”.

Dios, que es justo y capaz de hacer justicia, a menudo se ha asociado de manera contradictoria con la injusticia. En América Latina, como en el Israel de Amós, se ejerció el poder político para marginar, discriminar y esclavizar. El culto fue manipulado para ocultar injusticias y la Iglesia bendijo crímenes violentos.

Además de la violencia física, hay violencia estructural y simbólica. Cada vez que se viola el derecho de otra persona, se comete un acto de violencia (Liniker, 2019: 781).

Pero la violencia es concreta en el continente, como lo fue en los días de Amós. La pobreza y la miseria son la realidad de casi la mitad de los pueblos latinoamericanos. Y esto está protegido por estructuras de poder social e ideologías religiosas que aseguran el bienestar de la minoría.

El nombre de Dios es mal utilizado, ya sea por los gobernantes, que se presentan comollamados por Dios, o por expresiones populares sin significado. Todavía prevalece la idea de Dios de retribución y prosperidad, listo para pagar el mal con el mal o recompensar el bien con el bien, como justiciero y castigador (Silva, 2016: 900-903).

Esta historia fue diseñada políticamente para períodos de éxito similar en varios países: colonia, imperio, república y nación independiente. Este proceso histórico llegó, básicamente, a la Iglesia Católica Romana, de naturaleza hispana o portuguesa, según la colonización española o portuguesa. Fue un proyecto que unió la corona y la cruz, con las ambigüedades que conlleva dicha asociación.

$\mathrm{Si}$, por un lado, la Iglesia estaba del brazo del estado, apoyaba la subyugación de los indios, bendecía la esclavitud africana y favorecía las campañas de inmigración europeas, por el otro, proféticamente levantaba su voz contra la tergiversación de estas mismas prácticas injustas. Bajo el régimen de patrocinio, la Iglesia Católica otorgó a las coronas españolas y portuguesas derechos sobre las tierras conquistadas, y más 
tarde el Estado mantuvo a la Iglesia bajo control sin negar beneficios (Hoornaert, 1994: 293-296).

Contra las injusticias de la colonización, se alzaron voces proféticas a semejanza de Amós: Bartolomé de las Casas, Antonio de Montesinos, Juan de Sumárraga, Antonio Valdivieso, entre muchos otros. Estos leones rugientes faltan en la sociedad y la religión de hoy.

\section{A modo de conclusión}

En el curso de este artículo, pasamos exegéticamente por la realidad donde tiene lugar la experiencia profética de Amós y, hermenéuticamente, la forma en que se manifiesta hoy en día. En este advenimiento, concluimos, en cierta proporción, nuestro proceso de comprensión y aprehensión de la justicia en el mensaje del profeta de Técoa.

El horizonte en el que primero enfocamos nuestra atención estaba en el tema conflictivo existente entre aquellos que representaban legalmente el poder político y el corpus sagrado en el espacio inmanente: gobernantes y sacerdotes, en virtud de la justicia. En la comprensión profética de la justicia, los reyes y los sacerdotes ignoraron los preceptos establecidos en el Código de la Alianza, trazados entre Yahweh y el pueblo. Al final resultó que, en algún momento, los gobernantes, jueces y sacerdotes fueron tocados por la corrupción, la búsqueda del poder y el estatus, alejándose cada vez más de aquellos que deberían ser protegidos. En este enlace se establece el conflicto entre la casta sacerdotal y el profeta. La búsqueda constante de justicia social pone una tensión entre la jerarquía sacerdotal, legalmente constituida y reconocida, con la categoría profética, popular y espontánea.

A la luz de este contexto, a partir de una dinámica exegética de engendramiento, la justicia social se convierte en la fuerza impulsora que lanza el profeta Amós como el defensor de la justicia dentro de Israel y entre los pueblos vecinos. Como puede verse en una auditoría interna, la justicia social atraviesa todas las capas del libro de Amós o, como señalan algunos autores, las fases, etapas o composiciones del libro, el hecho de que el eco de sus golpes y los efectos de sus batallas sacudieron los cimientos de la comunidad israelita.

Dentro de este espectro analítico hemos entrado en un campo desafiante, el de hacer un corte bíblico y latinoamericano, en un intento por comprender las razones por las cuales la corrupción persiste en el sistema político y religioso. Y, por un lado, la palabra vehemente del profeta se pronunció como el portavoz de Dios, el león rugiente, en ataque directo contra las estructuras de poder, tanto palaciegas como religiosas, que causan injusticia. Por otro lado, y, por así decirlo, lo más importante, el mensaje de Amós reclamando justicia para los pobres, huérfanos y viudas se dio a conocer a nivel nacional e internacional, estableciendo el primer libro profético que se registra por escrito, superando los límites históricos.

El profeta campesino, el vaquero y cultivador de sicómoros, que denuncia la injusticia en el santuario del rey, nos invita hoy a apoyar a los pobres, marginados y oprimidos por nuestros sistemas sociales y religiosos. 


\section{Referencias citadas}

Aguirre, R. (1990): “Justicia. Perspectiva bíblica”, en Ellacuría, I. y Sobrino, J., eds., Mysterium Liberationis. II. Madrid, Trotta, pp. 539-561.

Bíblia de Jerusalém (2002). São Paulo, Paulus.

Bonora, A. (1983): Amós, o profeta da justiça, Tradução Pier L. Cabra, São Paulo, Paulinas. (Pequeno comentário Bíblico).

Frizzo, A. C (2011): “Uma tríade social que qualifica o ato de conhecer a Deus", Pistis \& Praxis, 3 (1), pp. 15-42.

Gonzalez, A. (1969): Profetismo y sacerdocio: Profetas, Sacerdotes y Reyes en el antiguo Israel, Madrid, Casa de la Biblia.

Hoornaert, E. (1994): História do Cristianismo na América Latina e no Caribe, São Paulo, Paulus.

Jaramillo Rivas, P. (1992): La injusticia y la opresión en el lenguaje figurado de los profetas. Estela, Verbo Divino (Institución San Jerónimo, 26).

Liniker, X. (2019): “O esmagamento do pobre a partir do profeta Amós: violações sociais em lugar da justiça”, Caminhos, 17 (2), pp. 771-790.

Disponível em: http://seer.pucgoias.edu.br/index. php/caminhos/article/view/7154. [Consultado em 01/11/2019].

Neher, A. (1975): La esencia del profetismo, Salamanca, Ediciones Sígueme.
Reimer, H. (1992): “Agentes e mecanismos de opressão e exploração em Amós”, Revista de Interpretação Bíblica Latino-Americana, 12, pp. 51-60.

Reimer, H. (2000): “Amós-profeta de juízo e justiça”, Revista de Interpretação Bíblica Latino-Americana, 35/36, pp. 171-190.

Sánchez Albornoz, C. (1974): Historia y libertad: ensayos sobre historiología, Madrid, Júcar.

Schökel, L. y Sicre Diaz, J. L. (1988): Profetas I: Isaías, Jeremias. São Paulo, Paulinas.

Schökel, L. y Sicre Diaz, J. L. (1991): Profetas II, Tradução Anacleto Alvarez, São Paulo: Paulinas (Grande Comentário Bíblico).

Schwantes, M. (2004): A terra não pode suportar suas palauras: reflexão e estudo sobre Amós, São Paulo, Paulinas.

Schwantes, M. (2013): O direito dos pobres, São Leopoldo, Oikos; São Bernardo do Campo. (Série Teses).

Sicre, J. L. (1990): Ajustiça social nos profetas, Tradução de Carlos Felício da Silveira, São Paulo, Paulinas. (Nova coleção bíblica).

Sicre, J. L. (1992): Introducción al Antiguo Testamento. Estella, Verbo Divino.

Silva, A. (2001): Amós: um profeta politicamente incorreto, São Paulo, Paulinas.

Silva, V. (2016): “Deus na linguagem proverbial: análise do uso do nome de Deus em provérbios e expressões 
populares da Bíblia e da atualidade", Horizonte, 14 (43), pp. 890-908.

Disponível em: http://periodicos.pucminas.br/index. php/horizonte/article/viewFile/P.2175-5841.2016v1 4n43p890/10219 [Consultado em 02/11/2019].

Tourn, G. (1978): Amós, profeta de la justicia, Traducción R. López; Versión original del hebreo J. A. Soggin, Buenos Aires, Tierra Nueva.

Vaz, A. D. S. (2019): “O específico da justiça na Bíblia hebraica”, Cultura [Online], 30, pp. 1-12, 2012, [Consultado em 31 outubro 2019].

Verkindère, G. (2001): La justicia en el Antiguo Testamento, Cuadernos Bíblicos, 105, Estella, Verbo Divino.

\section{Notas}

1 Las citas bíblicas generalmente siguen la traducción de la Biblia de Jerusalén (2002).

2 "Amós, el profeta de la justicia" es el título del libro de Bonora (1983). "Amós, profeta de la justicia" es otro libro de Tourn (1978).

3 Es importante aclarar que el sacerdote no es criticado por los profetas solo porque lo son, sino por sus pecados. "A su servilismo político se le ha agregado una ligereza ritual que desfigura completamente la ley” (NEHER, 1975, p. 256). Hubo un gran número de sacerdotes que permanecieron ejemplares en sus deberes y que la historia del sacerdocio no termina con la figura negativa de Amasias. También incluye el sacerdocio de Elí, Samuel, Elías, Ezequías, Josías y muchos otros siervos de la ley y de la adoración, de los cuales no fue objeto de un ataque profético. Por el contrario, el sacerdocio y el profetismo a menudo están en la misma persona, como Samuel, Elijah, Zacarías, Jeremías, Ezequiel y exaltaron su identidad espiritual (NEHER, 1975).

4 El huérfano y la viuda se encuentran entre las personas económicamente débiles a quienes la ley protege (Ex 22,21-22; Deut 10,18; 14,29; 27,19 etc.) y por quienes interceden los profetas (Jer 7,6; 22,3; 49.10-11; Is 1,23; 9,16; Ez 22,7).

5 "Jezabel no entra en Samaria con disposición a aceptar el credo o la adoración de Israel. Con ella viene un cuerpo de sirvientes fenicios, con su fe y sus prácticas religiosas. [...] El culto fenicio no solo disfruta de la libertad, sino que termina privándola de los pocos israelitas que permanecen fieles a la pureza javista" (GONZALEZ, 1969, p. 228). Neher(1975, p. 256) registra que, "en estos santuarios reina un espíritu sincrético: en Betely Dan, los toros Baal representaban al Dios de Israel. Y viceversa, dado que Jeú y la prohibición de adorar a Baal, la liturgia, consagrada oficialmente al Dios de Israel, va clandestinamente al ídolo cananeo".

6 Es digno de mención que, "la crítica que Amós dirige al sacerdote de la época, Amasias, no es ni puede ser un símbolo del profetismo contra el sacerdocio, ni un símbolo de la tradición hebrea contra el oportunismo clerical" (NEHER, 1975, p. 256). También es importante tener en cuenta las palabras de Sicre (1992, p. 423) que "para emitir un juicio sobre el pensamiento de los profetas sobre la adoración [y los sacerdotes] uno debe tener en cuenta todos los textos para evitar caerse en una postura simplista o simplificadora como algunos se han atrevido a hacer". 
7 El análisis de Jaramillo Rivas (1992, p. 203) es que “la intención de los poderosos es precisamente aplastar, masacrar a los pobres. Esta es una fuerte descripción de la situación de los oprimidos, víctimas de la maquinación de los poderosos".

8 Sicre (1992, p. 425) señala que, "Este fue un buen procedimiento para tranquilizar la conciencia. Al mismo tiempo, todas estas prácticas de culto fomentaron la idea de ser el pueblo elegido, mejor que ningún otro, como una garantía absoluta de protección divina y bendiciones". Al establecer un paralelismo entre los verdaderos fariseos y los falsos fariseos, Neher (1975, p. 256) cree que "los sacerdotes contra quienes los profetas atacaron de manera uniforme fueron los falsos fariseos. Están en una situación abusiva bajo la ley”.

9 Es posible que esta mención del jefe esté relacionada con toda la clase administrativa del período, que incluye a los sacerdotes directamente, ya que son los profesionales de mantenimiento del templo, como ya se señaló. 